\title{
PENGEMBANGAN MULTIMEDIA TUTORIAL POKOK BAHASAN STRUKTUR DAN FUNGSI TUBUH TUMBUHAN MATA PELAJARAN IPA
}

\author{
Arien Kurnia Putri, Sulton, Henry Praherdhiono \\ Jurusan Teknologi Pendidikan, Fakultas Ilmu Pendidikan, Universitas Negeri Malang \\ Jalan Semarang 5 Malang 65145 0341-574700 \\ arienkurniaptr@gmail.com
}

Article History

Received: 21 Juli 2020, Accepted: 21 Desember 2020, Published: 28 Mei 2021

\begin{abstract}
Abstrak
dalam proses belajar pada mata pelajaran ipa materi struktur dan fungsi tubuh pada tumbuhan. Pebelajar merasa kesulitan menghafalkan dan memahami struktur anatomi tumbuhan. Maka pemanfaatan multimedia tutorial dapat menjadi solusi untuk memotivasi pebelajar dan pembelajaran menjadi menyenangkan. Metode yang digunakan dalam penelitian ini adalah Lee \& Owens. Ada (lima) tahapan pengembangan produk yaitu Assessment/Analysis, Design, development, implementation, and Evaluation. Metode Lee \& Owens memiliki langkah-langkah pengembangan sistematis yang lebih mengutamakan hasil dari pengalaman penggunanya. Hasil review yang didapat dari ahli media, materi dan uji coba kepada pebelajar menunjukkan respon yang positif dan multimedianya layak digunakan dalam pembelajaran.
\end{abstract}

Keyword: Google Classroom; USE Questionnaries; Hasil Belajar

\begin{abstract}
The development of multimedia tutorials is carried out to assist students in the learning process in IPA subjects, material structure and body functions in plants. Students find it difficult to memorize and understand the anatomical structure of plants. So the use of multimedia tutorials can be a solution to motivate students in learning and learning to be more fun. The method used in this research is Lee \& Owens (2004: 3). There are (five) stages of product development, namely Assessment / Analysis, Design, development, implementation, and Evaluation. The Lee \& Owens Method has systematic development steps and prioritizes the outcome of the user experience. The results of the review obtained from media experts, materials and trials to students showed a positive response and the multimedia was suitable for use in learning
\end{abstract}

Keyword: Put 3-5 your keywords here in Bahasa Indonesia; keywords separated by semicolon 


\section{PENDAHULUAN}

Perkembangan revolusi industri 4.0 di Indonesia berdampak pada sistem Pendidikan Indonesia dimana informasi dan teknologi tersebar dengan luas dan mudah untuk diakses. Teknologi memiliki dampak besar dalam hal pendidikan (Saifudin, Susilaningsih \& Wedi, 2020). Pada proses pembelajaran, guru diharapkan untuk memiliki skill dan kreativitas yang tinggi dalam menghadapi tantangan perkembangan teknologi. Kualitas baik suatu bangsa dapat dinilai berdasarkan kualitas dalam pendidikannya. Pendidikan dapat diartikan sebagai aspek penting yang melekat untuk kehidupan setiap orang. Pada dasarnya pendidikan bagi pebelajar bertujuan untuk meningkatkan kemampuan, menjadikan pebelajar mampu mencapai proses pendewasaan diri dan kemandirian dalam belajar sehingga dapat menghadapi segala tantangan dan perubahan yang terjadi dalam kehidupan. Menurut (Undang-Undang Republik Indonesia, 1989) yang menyatakan bahwa "Pendidikan merupakan usaha sadar untuk menyiapkan pebelajar melalui bimbingan, pembelajaran dan latihan bagi perannya di masa yang akan datang".. Pembelajaran juga harus disesuaikan dengan perkembangan dan kebutuhan jaman. Menurut Billah (2015), kegiatan pembelajaran bisa terbantu oleh adanya teknologi sehingga dapat meningkatkan efektivitas belajar. Selain itu, pertimbangan jumlah guru, ketersediaan kelas hingga sarana dan prasarana harus dipantau agar pembelajaran dapat berjalan lancar dan pebelajar antusias dalam belajar, (Meliawati, 2016).

Pembelajaran memiliki berbagai unsur yang tidak dapat dipisahkan, antara lain kurikulum, pendidik, tujuan pembelajaran, pebelajar, materi bahan ajar, metode, media pembelajaran dan evaluasi. Unsur pembelajaran yang dapat dikembangkan dengan bantuan teknologi adalah media pembelajaran. Media pembelajaran dapat berupa visual (Nugrahani \& Rupa, 2007), audio (Mustika, 2015), dan audio visual (Purnomo, Yutmini, \& Anitah, 2014). Media pembelajaran yang menarik serta layak memberikan dampak positif pada kegiatan pembelajaran yang digunakan (Jatmika, 2005).

Media pembelajaran adalah sesuatu (alat, bahan, keadaan) yang digunakan sebagai perantara komunikasi antar pendidik dan pebelajar dalam proses pembelajaran (Capuno et al., 2019). Media pembelajaran memiliki peran mampu menunjang guru dalam menyampaikan materi pembelajaran sekaligus mengatasi masalah belajar pebelajar (Bahri, Hidayat \& Muntaha, 2018). Dalam hal ini, guru sebaiknya memanfaatkan multimedia interaktif untuk keberhasilan kegiatan pembelajaran. (Nurullah, 2019). Media yang sering digunakan dalam pembelajaran di kelas umumnya masih konvensional berupa Buku Paket, LKS dan Power Point. Menurut piramida pembelajaran (Edgar, 1970) manusia mampu mengingat rata-rata $10 \%$ dari apa yang telah di baca. Melalui penjelasan guru, pebelajar dapat mengingat rata-rata 20\%, dan penjelasan melalui tampilan gambar dan video, pebelajar dapat mengingat rata-rata $30 \%$. Dalam pembelajaran pasif, daya ingat dan kemampuan pebelajar lebih sedikit, karena pebelajar diposisikan sebagai partisipan. Sehingga media seperti buku paket, LKS, dan penjelasan dari guru dirasa masih belum efektif untuk menjadikan pebelajar aktif dan termotivasi dalam belajar (Ivić, 2019). Pebelajar memperoleh pemahaman dan daya ingat sebesar $70 \%$ melalui pembelajaran aktif dimana pebelajar dapat menyebutkan, mengajarkan, memberikan contoh, atau berdiskusi dengan pebelajar lainnya mengenai materi yang dipelajari. Keaktifan pebelajar saat mengimplementasikan ilmu atau materi yang dipelajari berkontribusi sebesar $90 \%$ atas pemahaman dan daya ingatnya.

Model pembelajaran yang bermutu mampu membantu pebelajar untuk mengembangkan diri secara optimal agar dapat mencapai tujuan pembelajaran dan proses pembelajaran dapat berpusat kepada pebelajar (student centered) (Corley, 2012; Hesson \& Shad, 2007; Neill \& Mcmahon, 2005). Metode konvensional telah terbukti kurang mampu memberikan hasil maksimal pada hasil belajar pebelajar, maka pendekatan menggunakan media tutorial paling cocok dijadikan perantara dala proses pembelajaran. Tutorial sendiri berpusat pada latihan berulang sehingga pebelajar dapat memahami materi yang telah diajarkan. Media ini dilengkapi dengan pertanyaan dan adanya skor hasil latihan soal. Pembelajaran menggunakan media berupa tutorial biasanya digunakan pada materi memahami atau menghafal macam-macam fungsi. Pemanfaatan media tutorial cocok diaplikasikan dalam pembelajaran IPA pada materi jaringan tumbuhan. Melalui multimedia pembelajaran tutorial ini pebelajar dapat memahami struktur tumbuhan dan fungsi dari bagian-bagian tumbuhan dengan mudah dan menyenangkan sehingga pebelajar tertarik dan tidak merasa bosan.

Berdasarkan observasi yang telah dilakukan di SMPN 14 Malang, diketahui bahwa sekolah telah menyediakan beberapa media pembelajaran, diantaranya LCD proyektor dan komputer. Selain itu untuk 
menunjang kegiatan pembelajaran, sekolah juga memiliki laboratorium bahasa dan laboratorium komputer. Fasilitas-fasilitas tersebut sudah disediakan sekolah namun ternyata dalam pembelajaran media tersebut belum mampu dimanfaatkan secara optimal. Komputer merupakan media yang memiliki kemampuan interaksi paling baik. Namun pemanfaatan komputer sebagai media kurang optimal karena belum tersedia media pembelajaran berbasis komputer yang dimanfaatkan di sekolah.

Penyajian materi pada model tutorial ini memiliki tampilan panduan dengan tutor dan alat pengontrol yang dikendalikan oleh pengguna, kemudian sistem menampilkan informasi sesuai pengoperasian yang dilakukan oleh pengguna. (Hamalik 2003: 73) menjelaskan, memanfaatkan model tutorial dapat menaikkan keaktifan pebelajar saat kegiatan pembelajaran berlangsung. Dengan memanfaatkan model tutorial memungkinkan pebelajar dapat mengatasi problem belajar mandiri, sehingga proses pembelajaran dapat terpusat pada pebelajar. Tujuan pengembangan adalah menghasilkan sebuah produk multimedia tutorial IPA pada pokok bahasan Struktur dan Fungsi Tubuh Tumbuhan, yaitu media berupa aplikasi sederhana yang mudah digunakan oleh pebelajar selama proses pembelajaran serta memberikan solusi terhadap masalah menurunnya hasil belajar, minat baca, memahami dan kemampuan menghafal pebelajar menjadi lebih kongkrit (nyata) pada pebelajar kelas VIII. Penelitian ini menggunakan model pengembangan (Lee \& Owens 2004:3). Ada (lima) tahap pengembangan produk yaitu Assessment/Analysis, Design, development, implementation, and Evaluation.

Pengembangan tutorial ini dirancang secara bercabang agar materi dapat dipelajari sesuai dengan keinginan pebelajar dan memberikan pengetahuan secara tuntas kepada pebelajar secara fleksibel (Darmawan, 2014), Dalam hal ini multimedia tutorial juga diciptakan guna menarik pebelajar dalam belajar, mempermudah penyerapan materi yang diberikan juga memudahkan pebelajar dalam menghafalkan beberapa bagian-bagian tumbuhan dan fungsinya.

\section{METODE}

Model yang digunakan adalah model pengembangan multimedia menurut (Lee \& Owens, 2004). Tahapan-tahapan yang terdapat dalam model ini terdapat pada gambar 1:

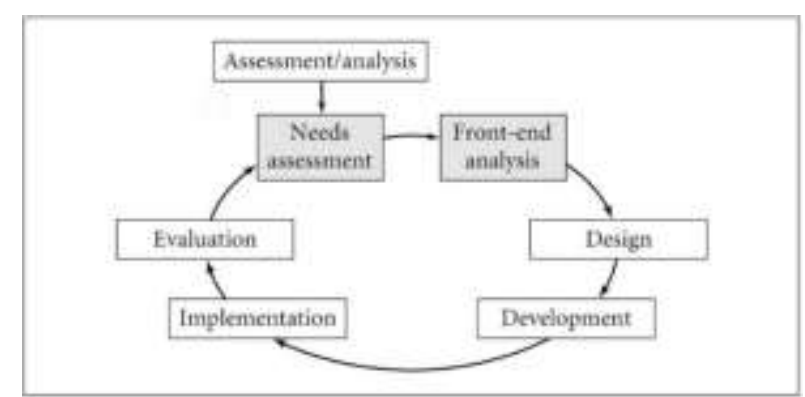

Gambar 1. Model Penelitian dan Pengembangan (Lee \& Owens 2004:3)

Alasan pemilihan model Lee \& Owens (2004) karena memiliki prosedur yang tepat untuk mengembangkan multimedia pembelajaran, langkah-langkahnya tersusun secara sistematis serta langkah pengembangannya jelas dan model pengembangan ini mengutamakan pengalaman penggunaanya dan juga model ini pada dasarnya ditujukan untuk pengembangan multimedia pembelajaran. Dalam model ini juga menyediakan desain intruksional yang jelas dalam mengembangkan angket, serta mencantumkan respon dari pengalaman penggunaan multimedia yang digunakan. Sehingga, dapat menghasilkan produk yang sesuai dan layak untuk digunakan secara luas. Model pengembangan ini memiliki enam tahap yaitu Asesment Kebutuhan dan Front-end Analysis, Desain, Pengembangan, Implementasi, dan Evaluasi.

Namun dalam penelitian ini hanya menggunakan empat tahap dalam pengembangan produknya yaitu; tahap assessment/analisis terdiri dari Need Assessment yaitu merupakan analisis kebutuhan yang dilakukan dengan cara wawancara langsung kepada narasumber dan observasi langsung di tempat penelitian untuk mengetahui keadaan sekolah. Sedangkan Front-End Analysis yaitu dilakukan untuk memperoleh informasi yang lebih terperinci untuk media yang dikembangkan.. 
Pada tahap desain dilakukan perencanaan produk yang dihasilkan, seperti membuat struktur konten, desain antarmuka serta komponen lain yang perlu dirancang seperti, video penunjang, tujuan pembelajaran hingga petujuk penggunaan, karena struktur konten merupakan tahap penting dalam menciptakan suatu media. Tahapan desain juga mengacu pada alur multimedia pembelajaran pada model tutorial.

Pada tahap pengembangan, media pembelajaran ini dibuat dengan meggunakan software utama Autoplay Studio 8 dan peralatan pendukung lainnya. Tujuannya adalah mengembangkan produk media digital berupa multimedia tutorial. Pengembangan instrumen juga dilakukan guna menguji kelayakan media pembelajaran pada ahli media dan ahli materi.

Pada tahap development, dibutuhkan berbagai macam keterampilan dalam mengembangkan produk digital berupa multimedia tutorial ini. Keterampilan yang dibutuhkan diantaranya adalah mengembangkan storyboard, desain interface dan lain-lain dan menghasilkan multimedia tutorial yang layak dan menarik.

Tahap implementasi dan evaluasi belum dilakukan karena masih dalam tahap uji kelayakan atas perangkat dengan tahap kesiapan teknologi pada peringkat 4 (validasi kode, komponen dan atau kumpulan dalam lingkup laboratorium). Dalam penelitian ini terdapat dua ahli untuk menguji kelayakan produk yaitu ahli materi yang masing-masing berjumlah satu orang yaitu guru IPA di SMPN 14 Malang dan ahli media yaitu salah satu dosen Teknologi Pendidikan UM. Dalam penilaian kelayakannya, produk ini menggunakan angket yang didalmnya terdapat 20 pernyataan. Analisis data menurut Lee \& Owens (2004) adalah dengan menggunakan rating scale yang dipengaruhi oleh total data dan respon yang didapat setiap pernyataan pada angket. Berikut adalah penilaian kriteria tingkat kelayakan pada angket: Sangat Setuju bernilai (4), Setuju bernilai (3), Tidak setuju bernilai (2), dan Sangat tidak setuju bernilai(1).

\section{HASIL}

Data uji kelayakan multimedia tutorial berasal dari hasil penilaian ahli media oleh salah satu dosen Teknologi Pendidikan UM dan dari guru IPA di SMPN 14 Malang. Hasil data yang didapat ada dua, yaitu data kuantitatif berupa angka dan saran-saran.

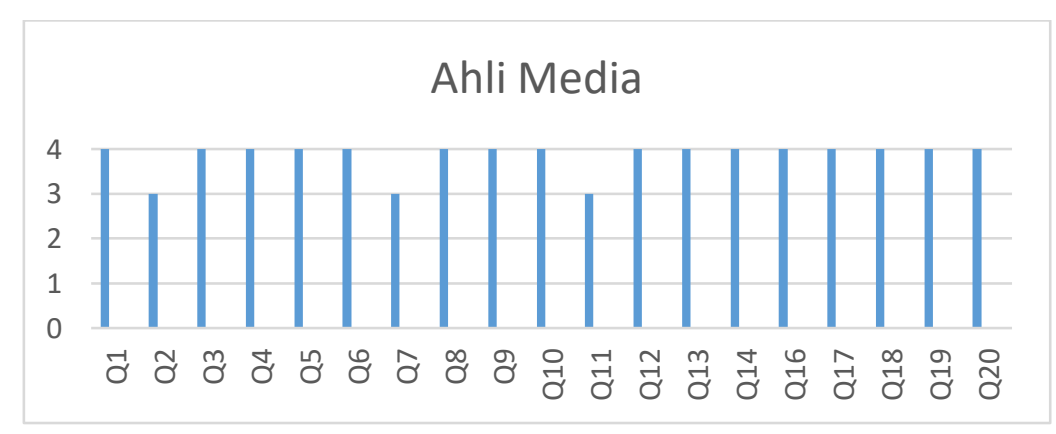

Gambar 2 Grafik batang tanggapan ahli media

Berdasarkan gambar 2, multimedia tutorial bernilai positif dan layak, karena dari hasil review ahli media dari penyajian 20 pernyataan diatas terdapat 17 pernyataan bernilai 4 , dan 3 pernyataan bernilai 3. Ahli media juga memberikan respon bahwa desain dan tampilan multimedia tutorial sudah sangat menarik, komposisi warna dan layout juga sudah bagus. Terdapat catatan, yaitu masih perlu diperbaiki untuk beberapa halaman yang tidak ada gambar, tata letak pada multimedia tutorial, tingkat kemenarikan huruf. 


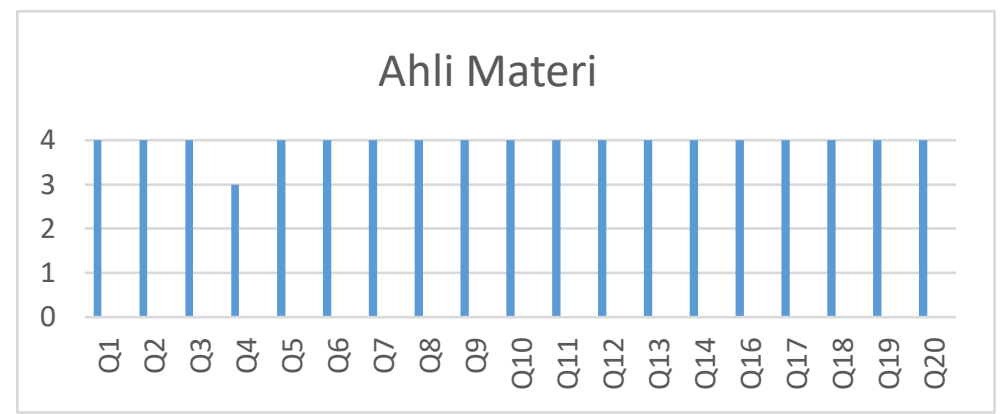

Gambar 3 Grafik batang tanggapan ahli materi

Berdasarkan gambar 3, multimedia tutorial bernilai positif dan layak karena hasil review ahli materi dari penyajian 20 pernyataan diatas terdapat 19 pernyataan bernilai nilai 4 dan 1 pernyataan bernilai 3. Ahli media juga memberikan respon bahwa desain dan tampilan multimedia tutorial sudah sangat menarik, komposisi warna dan layout juga sudah bagus. Terdapat catatan yang dapat ditambahkan yaitu perlu diperbaiki untuk kemenarikan multimedia tutorial secara keseluruhan dengan menambahkan gambar, mengatur tata letak, dan mengubah font untuk kemenarikan huruf.

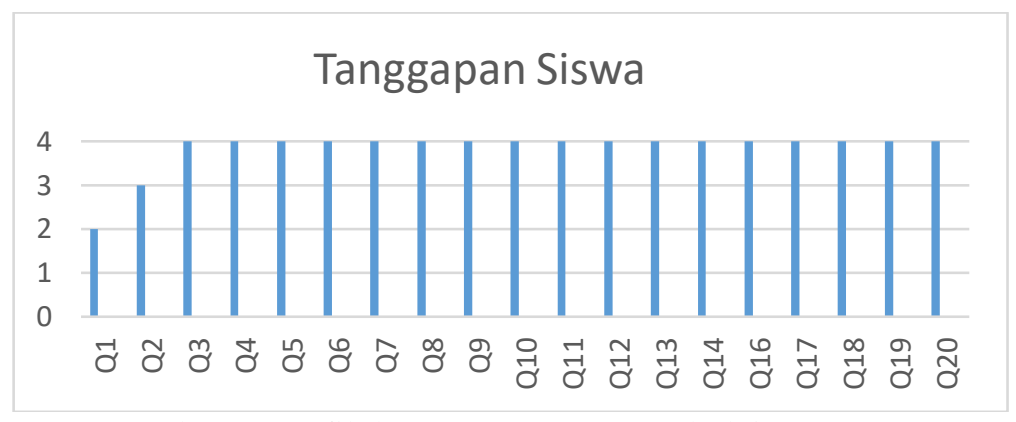

Gambar 4 Grafik batang tanggapan pebelajar

Berdasarkan gambar 4, multimedia tutorial bernilai positif dan layak karena dari penyajian 20 pernyataan terdapat 18 pernyataan bernilai 4 dan 2 pernyataan bernilai 3 dan 2. Pebelajar juga memberikan respon bahwa desain dan tampilan multimedia tutorial sudah sangat menarik, komposisi warna dan layout juga sudah bagus. Terdapat catatan agar petunjuk penggunaan lebih diurutkan secara sistematis, agar pemanfaatan media lebih efektif.

Dari review dan uji coba yang telah dilakukan, multimedia tutorial layak digunakan pada mata pelajaran IPA materi Struktur dan Fungsi Tubuh Tumbuhan. Hasil pengembangan ini telah disetujui oleh ahli media dan ahli materi. Namun multimedia tutorial terdapat sedikit perbaikan pada petunjuk penggunaan lebih diurutkan secara sistematis, menambahkan gambar, mengatur tata letak, dan mengubah font untuk kemenarikan huruf.

\section{PEMBAHASAN}

Pemanfaatan media pembelajaran interaktif dalam proses pembelajaran merupakan salah satu bentuk pelaksanaan kemajuan teknologi dan komunikasi, khususnya dalam bidang pendidikan. Pemanfaatan multimedia interaktif juga dapat meningkatkan aktivitas memori pebelajar sekaligus mampu menghemat waktu (Jannah, Copriady \& Rasmiwetti, 2019). Menurut Widayat (2014) pemanfaatan multimedia interaktif dalam kegiatan pembelajaran mampu mengembangkan ketrampilan pebelajar menjadi lebih baik.

Pada kegiatan pembelajaran, media pembelajaran tidak sekedar berfungsi menjadi alat bantu, media pembelajaran sudah termasuk bagian integral dalam kegiatan pembelajaran (Musfiqon, 2012). Media pembelajaran ini dikembangkan menggunakan model pengembangan Lee \& Owens (2004). Hasil dari pengembangan merupakan sebuah produk media pembelajaran multimedia tutorial pokok bahasan struktur dan fungsi tubuh tumbuhan mata pelajaran IPA dengan bantuan perangkat lunak AutoPlay Media Studio 8. 
Permasalahan yang terjadi pada pembelajaran IPA adalah pembelajaran kovensional yang masih berfokus pada guru, dimana pebelajar hanya sebagai audiens yang membuat tingkat partisipasi pebelajar dalam pembelajaran sangat kurang sehingga pembelajaran menjadi kurang bermakna bagi pebelajar dan pebelajar cepat merasa bosan. Sary (2018) menyatakan, multimedia interaktif mencakup gabungan dari gambar, tulisan, audio, animasi dan video yang dapat digunakan sendiri oleh penggunanya. Menurut Rifani (2014) pemanfaatan multimedia interaktif berpengaruh pada hasil belajar dan memotivasi pebelajar dalam belajar. Penggunaan multimedia tutorial sebagai media pembelajaran ini dapat mengubah pembelajaran yang tadinya berpusat pada guru menjadi pembelajaran yang berpusat pada pebelajar.

Pada penelitian sebelumnya oleh Mawarni, Sella \& Muhtadi, Ali (2017) menjelaskan jika pemanfaatan model tutorial bermanfaat bagi mahapebelajar sebagai sumber belajar mandiri. Tetapi dalam pengoperasiannya, media ini tidak ditampilkan action script gotoAndPlay untuk menghubungkan fungsi tombol (button) dengan materi atau konten yang berkaitan. Penelitian sebelumnya oleh Maryana, pengembangan media Autoplay dalam pembelajaran kelas X mampu meningkatkan konsentrasi belajar dan hasil belajar. Mayoritas hasil pengalaman dari penelitian sebelumnya, multimedia tutorial sesuai untuk digunakan sebagai media pembelajaran dalam membantu belajar dalam kegiatan pembelajaran. Proses belajar pebelajar menjadi lebih efektif, namun terdapat kekurangan pada materi yang disajikan agar sesuai dengan kemampuan pebelajar.

Pengembangan multimedia tutorial ini merupakan penyempurnaan dari penelitian pengembangan yang telah dilakukan sebelumnya. Pada pengembangan multimedia tutorial yang dikembangkan ini didukung dengan adanya gambar-gambar dan video yang ditampilkan guna menarik perhatian pebelajar, terdapat soal kuis yang dilengkapi dengan hasil saat soal selesai dikerjakan. Video sebagai pendukung agar pebelajar lebih mudah memahami materi yang ditampilkan dan terdapat action script gotoAndPlay untuk menghubungkan fungsi tombol (button) dengan materi atau konten yang berkaitan. Menurut Rokhayani (2019) dalam pembelajaran melalui multimedia interaktif, pebelajar dimungkinkan untuk melakukan pengulangan materi yang sudah dipaparkan atau dijelaskan. Yunita (2019) menyatakan, media merupakan bagian utama dalam kegiatan belajar mengajar dan tidak hanya sebagai menjadi alat bantu dalam mengajar. Hal itu sama dengan pernyataan (Surahman, 2019) bahwa kemampuan guru merancang pembelajaran dapat mempengaruhi media yang menjadi unsur utama dalam pembelajaran. Pernyataan tersebut dapat dibuktikan dari hasil data tentang kelayakan media untuk dimanfaatkan dalam proses pembelajaran. Kelebihan dan kekurangan juga dimiliki dalam penggunaan media pembelajaran tutorial ini. Produk yang dikembangkan diuji kelayakannya kepada ahli media, ahli materi, dan diuji cobakan pada pebelajar. Pernyataan yang berkenaan dengan materi yang disajikan dalam multimedia tutorial berjumlah 20 pernyataan

Dari hasil review oleh ahli media dengan 20 pernyataan yang disajikan kepada ahli media, terdapat 18 pernyataan yang mendapat pilihan Sangat Setuju yang bernilai 4 yang masuk dalam kriteria layak, yaitu: (3) Media memuat Kompetensi Dasar dan Indikator; (4) Tujuan pembelajaran sesuai dengan indikator; (5) Tujuan pembelajaran sesuai dengan kompetensi dasar; (6) Penggunaan media sesuai model pembelajaran yang diterapkan; (7) Keserasian pokok materi dengan judul; (8) Ketepatan penerapan strategi belajar (mandiri); (9) Ruang lingkup materi memadai; (10) Kedalaman materi memadai; (11) Penyajian materi runtut; (12) Bahasa yang digunakan mudah dipahami; (13) Gambar, animasi dan video memudahkan pemahaman materi; (Q14) Media pembelajatan dilengkapi dengan hasil nilai yg muncul; (15) Penyajian isi materi sudah menarik dan dapat memotivasi; (16) Penyajian materi dapat menumbuhkan kesenangan; (17) Penyajian materi dapat menumbuhkan keaktifan pebelajar; (18) Penyajian materi dapat membuat pebelajar betah untuk belajar; (19) Penyajian materi memudahkan pebelajar dalam mencapai tujuan belajar; (20) Media pembelajaran tutorial dirasa efektif dalam penggunaannya. Sedangkan pada pernyataan lain yang mendapat pilihan Setuju bernilai 3 dan Kurang Setuju bernilai 2 yang termasuk dalam kriteria cukup layak yaitu: (1) Petunjuk penggunaan media sistematis; (2) Petunjuk mengerjakan sudah jelas. Analisis yang telah dilakukan terhadap tanggapan responden ahli materi bernilai positif dan layak untuk digunakan. Terdapat catatan yang dapat ditambahkan yaitu petunjuk penggunaan lebih diurutkan secara sistematis, agar pemanfaatan media lebih efektif.

Sedangkan dari hasil review ahli materi dengan 20 pernyataan yang diujikan kepada ahli materi, terdapat 19 pernyataan mendapat pilihan Sangat Setuju yang bernilai 4 dengan kategori layak, yaitu: (1) 
Materi yang disajikan sesuai dengan tujuan pembelajaran; (2) Audio yang ada di icon/ tombol pada multimedia tutorial mudah untuk dipahami; (3) Kesesuaian teks, gambar, dan animasi, dengan materi yang disampaikan; (4) Petunjuk pemanfaatan multimedia tutorial dapat membantu pebelajar; (6) Kesesuaian antara evaluasi/ latihan soal yang diberikan dengan materi pelajaran; (7) Penggunaan multimedia tutorial mampu mempermudah pebelajar dalam memahami materi pelajaran; (8) Ketepatan penggunaan contoh video terkait dengan materi dalam multimedia tutorial; (9) Media pembelajaran multimedia tutorial dapat memotivasi pebelajar dalam proses pembelajaran; (10) Ketepatan penggunaan kalimat penting atau penekanan dalam materi; (11) Materi yang tersaji berpotensi mampu menambah wawasan dan pengetahuan pebelajar; (12) Media pembelajaran multimedia tutorial sesuai untuk digunakan dalam kegiatan pembelajaran pebelajar secara individu atau mandiri; (13) Bahasa yang digunakan dalam penyajian materi pada multimedia tutorial ini komunikatif; (14) Kejelasan teks atau tulisan; (15) Kesesuaian petunjuk pemanfaatan dalam pengoperasian media; (16) Kejelasan judul pada halaman awal; (17) Kesesuaian urutan isi materi; (18) Kesesuaian Bahasa; (19) Kesesuaian isi materi sesuai dengan buku paket; (20) Kesesuaian materi dengan tingkat pemahaman. Sedangkan pada pernyataan lain yang mendapat pilihan Setuju yang bernilai 3 dan termasuk dalam kriteria cukup layak yaitu: (5) Kemenarikan multimedia tutorial secara keseluruhan; Analisis yang telah dilakukan terhadap tanggapan responden ahli materi diperoleh bernilai positif dan layak untuk digunakan. Terdapat catatan yang dapat ditambahkan yaitu perlu diperbaiki untuk kemenarikan multimedia tutorial secara keseluruhan dengan menambahkan gambar, mengatur tata letak, dan mengubah font untuk kemenarikan huruf.

Pada hasil tanggapan pebelajar dengan 20 pernyataan yang diujikan kepada ahli materi, terdapat 17 pernyataan mendapat pilihan Sangat Setuju yang bernilai 4 yang masuk dalam kategori layak, yaitu: (1) kejelasan petunjuk penggunaan; (3) tingkat kemudahan dalam mengoperasikan; (4) tingkat kemenarikan desain interface; (5) kemenarikan icon yang ada pada tombol menu; (6) Kesesuaian icon tombol dengan fungsinya; (8) ketepatan pemilihan background gambar; (9) kemenarikan komposisi warna; (10) ketepatan alur/ sistematika; (11) tingkat kemenarikan jenis huruf; (12) kesesuaian ukuran huruf; (13) ketepatan pemilihan warna huruf terhadap kalimat penting; (14) kejelasan teks/tulisan; (15) kesesuaian audio dengan icon/ tombol; (16) kualitas video; (17) kejelasan gambar; (18) kualitas animasi; (19) kejelasan evaluasi atau latihan soal; (20) tingkat interaktifitas. Sedangkan pada pernyataan mendapat pilihan Setuju yang bernilai 3 dan termasuk dalam kategori cukup layak yaitu: (2) Kemenarikan desain setiap slide; (7) ketepatan tata letak menu dan tombol; (11) Tingkat kemenarikan jenis huruf. Analisis yang telah dilakukan pada ahli media diperoleh nilai positif dan layak untuk digunakan. Terdapat catatan yang dapat ditambahkan yaitu perlu diperbaiki untuk beberapa halaman yang tidak dilengkapi gambar, tata letak pada multimedia tutorial, tingkat kemenarikan huruf.

Penggunaan media tutorial pada kegiatan belajar di kelas telah terbukti secara konkrit mampu membantu guru dalam menyampaikan materi pembelajaran. Pemanfaatan multimedia tutorial pada proses pembelajaran juga telah terbukti dapat memotivasi pebelajar saat belajar sehingga hasil belajar pebelajar mengalami peningkatan. Dalam hal ini pebelajar juga dapat ikut serta dalam memanfaatkan perkembangan kemajuan teknologi. Hal ini sesuai pendapat (Wardani 2019) yang menyatakan, salah satu alternatif agar proses pembelajaran menjadi berkualitas adalah dengan memanfaatkan multimedia interaktif sebagai media pembelajaran.

\section{SIMPULAN}

Multimedia tutorial merupakan sebuah solusi untuk memberikan kemudahan dalam meningkatkan kemampuan pemahaman dan menyelesaikan masalah-masalah dalam proses belajar secara mandiri. Multimedia tutorial ini memiliki kelebihan yang mana pebelajar dapat terlibat langsung dalam mengoperasikan media tersebut secara leluasa dan dapat mengulangi materi jika dirasa kurang paham. Penggunaan media tutorial juga dirasa efektif dan efisien bagi guru untuk memberikan materi kepada pebelajar.

Dalam penelitian ini terdapat dua ahli untuk menguji kelayakan produk yaitu ahli materi dan ahli media. Berdasarkan review ahli materi didapatkan jika multimedia tutorial dikatakan layak digunakan Berdasarkan review ahli media didapatkan jika multimedia tutorial layak untuk digunakan. Hanya ada kekurangan dengan saran perbaikan oleh ahli media yaitu pada multimedia tutorial sebaiknya diberi audio di awal tampilan. Uji coba produk juga dilakukan pada kelompok kecil dan didapatkan hasil bahwa multimedia tutorial ini mampu menunjang hasil belajar dan memotivasi untuk belajar, pebelajar 
lebih mudah memahami materi yang diajarkan. Multimedia tutorial ini memiliki kelebihan dengan dilengkapi latihan soal atau kuis. Sehingga multimedia tutorial ini mampu menghantarkan pesan kepada pengguna agar mempermudah dalam memahami materi yang telah disajikan.

\section{DAFTAR RUJUKAN}

Bahri, A., Hidayat, W., \& Muntaha, A. Q. (2018). Penggunaan Media Berbasis AutoPlay Media Studio 8 Untuk Meningkatkan Aktivitas dan Hasil Belajar Siswa: Sebuah Inovasi Media Pembelajaran. In Proceeding Biology Education Conference: Biology, Science, Enviromental, and Learning (Vol. 15, No. 1, pp. 394-402).

Billah, A. F. (2015). Pemanfaatan Media Teknologi Informasi dan Komunikasi dalam ImplementasiKurikulum 2013 Bandung: repository.upi.edu.

Capuno, R., Revalde, H., Etcuban, J. O., Aventuna, M., Medio, G., \& Demeterio, R. A. (2019). Facilitating Learning Mathematics Through the Use of Instructional Media. International Electronic Journal of Mathematics Education, 15(1), 677-688. https://doi.org/10.29333/iejme/5785

Darmawan, D. (2014). Inovasi Pendidikan: Pendekatan Praktik Teknologi Multimedia dan Pembelajaran Online. Bandung: PT Remaja Rosdakarya

Ghasemi, B., Hashemi, M., \& Bardine, S. H. (2011). The Capabilities of Computers for Language Learning. Procedia - Social and Behavioral Sciences, $2858-62$.

Hamalik, O. (2003). Perencanaan pengajaran berdasarkan pendekatan sistem. Bumi Aksara.

Hesson, M., \& Shad, K. F. (2007). A Student-centered Learning Model. American Journal of Applied Sciences, 4(9), 628-636. https://doi.org/10.3844/ajassp.2007.628.636

Ivić, I. (2019). Printed and digital media: Printed and digital textbooks. Center for Educational Policy Studies Journal, 9(3), 25-49. https://doi.org/10.26529/cepsj.694

Jannah, M., Copriady, J., \& Rasmiwetti, R. (2019). Development of Interactive Learning Media using Autoplay Media Studio 8 for Colloidal Chemistry Material. Journal of Educational Sciences, 3(1), 132-144

Jatmika, H. M. (2005). Pemanfaatan Media Visual dalam Menunjang Pembelajaran Pendidikan Jasmani di Sekolah Dasar. Jurnal Pendidikan Jasmani Indonesia, 3(1), 89-99.

Lee, W. W., \& Owens, D. L. (2004). Multimedia-based instructional design: computer-based training, web-based training, distance broadcast training, performance-based solutions. John Wiley \& Sons.

Mawarni, Sella \& Muhtadi, Ali. (2017). Pengembangan Digital Book Interaktif Mata Kuliah Pengembangan Multimedia Pembelajaran Interaktif Untuk Mahasiswa Teknologi Pendidikan. Jurnal Inovasi Teknologi PendidikanVol 4 (1). 84-96

Mayer, R. E., \& Moreno, R. (1998). A cognitive theory of multimedia learning: Implications for design principles. Journal of Educational Psychology, 91(2), 358-368.

Meliawati, W. (2016). Survei Pelaksanaan Lintas Minat Pada Mata Pelajaran Biologi Beserta Analisis Kendala Pelaksanaan di SMA Negeri Se Kota Malang. SKRIPSI Jurusan Biologi-Fakultas MIPA UM. https:www.munirarber.blogspot.com/2012/07/tentang-auto-play-media-studio.html?m=1

Musfiqon, H. M. (2012). Pengembangan Media dan Sumber Pembelajaran. Jakarta: PT. Prestasi Pustakakarya

Mustika, R. (2015). Media Pembelajaran Sistem Audio untuk Pemberdayaan Pendidikan di Komunitas Masyarakat. Jurnal Masyarakat Telematika Dan Informasi, 6(1), 57-68. https://doi.org/http://dx.doi.org/10.17933/mti.v6i1.75

Nugrahani, R., \& Rupa, J. S. (2007). Media Pembelajaran Berbasis Visual Berbentuk Permainan Ular Tangga untuk Meningkatkan Kualitas Belajar Mengajar di Sekolah Dasar. Lembaran Ilmu Kependidikan, 36(1), 35- 44. 
Nurullah, A., Soepriyanto, Y., Sulton, S., \& Husna, A. (2019). Pengembangan Multimedia Pembelajaran Energi dalam Sistem Kehidupan. Jurnal Kajian Teknologi Pendidikan, 2(4), 315-319.

Purnomo, J., Yutmini, S., \& Anitah, S. (2014). Penggunaan Media Audio-Visual Pada Mata Pelajaran Ilmu Pengetahuan Alam Di Sekolah Menengah Pertama Negeri. Jurnal Teknologi Pendidikan Dan Pembelajaran, 2(2), 127-144.

Rifani, A. C. (2014). Pengembangan media pembelajaran Ilmu Pengetahuan Sosial berbasis Macromedia Flash 8 pada materi perkembangan kemajuan teknologi untuk kelas IV Madrasah Ibtidaiyah Miftahul Huda Sidoarjo (Doctoral dissertation, Universitas Islam Negeri Maulana Malik Ibrahim).

Rokhayani, D., Kuswandi, D., \& Abidin, Z. (2019). Multimedia Interatif Berbasis Game Kelas X Sekolah Menengah Atas. Jurnal Kajian Teknologi Pendidikan, 2(2), 102-108.

Saifudin, M. Fahmi, Susilaningsih, Wedi, A. (2020). Pengembangan Multimedia Interaktif Materi Sumber Energi Untuk Memudahkan Belajar Siswa. Jurnal Kajian Teknologi Pendidikan,3(1) 68 77.

Hidayah, Sary Nur, Sihkabuden, Praherdhiono, Henry. (2018). Pengembangan Multimedia Interaktif Seni Tari Jawa Timur Pada Mata Pelajaran Seni Budaya Kelas VII di SMP Negeri 1 Karangan. Jurnal Kajian Teknologi Pendidikan,1(1) 63-69

Undang-Undang Republik Indonesia. (1989). Undang-Undang Republik Indonesia. In Undang-Undang Republik Indonesia. Citra Umbara..

Wardani, S. K., Setyosari, P., \& Husna, A. (2019). Pengembangan Multimedia Tutorial Mata Pelajaran Ipa Pokok Bahasan Sistem Tata Surya Kelas Vii Mts Raudlatul Ulum Karangploso. Jurnal Kajian Teknologi Pendidikan, 2(1), 23-29.

Widayat, W., Kasmui, K., \& Sukaesih, S. (2014). Pengembangan multimedia interaktif sebagai media pembelajaran ipa terpadu pada tema sistem gerak pada manusia. Unnes Science Education Journal, $3(2)$.

Yunita, R., Praherdhiono, H., \& Adi, E. P. (2019). Pengembangan Multimedia Interaktif Materi Fotosintesis untuk Siswa Kelas VIII Sekolah Menengah Pertama. Jurnal Kajian Teknologi Pendidikan, 2(4), 284-289 